\title{
STUDY ON THE CD (II) ADSORPTION CHARACTERISTICS OF DIFFERENT SALINE-ALKALINE SOILS IN WESTERN JILIN PROVINCE, CHINA
}

\author{
MA, X. L." -ZHANG, J." - YAN, T. Y.\# - SUN, J. - WANG, J. H. - FENG, J. - WANG, H. B. \\ College of Resources and Environment, Jilin Agricultural University, Changchun 130118, China \\ ${ }^{\#}$ These authors contributed equally to this work \\ *Corresponding author \\ e-mail:814634273@qq.com; phone: +86-130-3901-0128
}

(Received 29 $9^{\text {th }}$ Aug 2019; accepted $25^{\text {th }}$ Nov 2019)

\begin{abstract}
In order to effectively control the environmental behavior of cadmium in saline-alkaline soil, it is imperative to understand its adsorption capacity. In this study, the kinetics, adsorption isotherm and two environmental parameters ( $\mathrm{pH}$ and addition of biochar) of the adsorption behavior of $\mathrm{Cd}$ (II) in three saline-alkaline soil samples from western Jilin province, China were investigated. This study was an optimal fit for the pseudo-second-order kinetics model, as well as Langmuir adsorption isotherm model. The adsorption effect was the strongest at a $\mathrm{pH}$ of 7, the addition of biochar could increase $\mathrm{Cd}$ (II) adsorption of the soil. The adsorption of Cd (II) by saline-alkaline soil was a spontaneous, disordered and heat-absorbing reaction. Compared with mildly and moderately saline-alkaline soil, the adsorption of $\mathrm{Cd}$ (II) by severely saline-alkaline soil was the highest, and the adsorption was the best when the $\mathrm{pH}$ was neutral. Moreover, the addition of biochar could increase the organic matter in the soil and improve the adsorption capacity of Cd (II).
\end{abstract}

Keywords: heavy metal, saline-alkali soil, properties, $\mathrm{pH}$, biochar

\section{Introduction}

Saline-alkaline soil is a common soil type on Earth, accounting for about $7 \%$ of the total soil area of the world. It is widely distributed in arid and semi-arid regions of Asia, Australia, Africa and South America (Yang et al., 2018; Saifullah et al., 2018). China ranks third in the world in terms of saline-alkaline soil area, mainly distributed in the northeast, north China, northwest inland and coastal areas along the Yangtze River. In the western region of Jilin province, there are 3.2 million $\mathrm{hm}^{2}$ of saline-alkali soil, which is one of the three most concentrated saline-alkali areas in the world (Shi et al., 2018), which has brought serious harm to the development of agriculture and animal husbandry in Songnen plain (Zhao et al., 2018; He et al., 2008).

With the rapid development of industrial and agricultural production, the sources of heavy metals in soil, including the use of pesticides, excessive application of chemical fertilizers, industrial wastewater, bio-fats and so on (Ashraf et al., 2019), especially phosphate fertilizer containing relatively high concentrations of cadmium, which is different deposits varies greatly, and the overall average concentration of cadmium in sediments is $21 \mathrm{mg} / \mathrm{kg}$, ranging from 1 to $150 \mathrm{mg} / \mathrm{kg}$ (Roberts, 2014). Soil cadmium pollution is a serious problem in China and is the main cause of cadmium contaminated rice (Wu et al., 2018). According to 2014 National Soil Pollution Survey data, $16.1 \%$ of the soil pollution sites (including agriculture and industry) exceeded the allowable limit of the second-level soil environmental quality standards, among which heavy metal pollution sites accounted for $82.8 \%$. Among them, cadmium exceeded the standard by 
7.0\% (He et al., 2019), and heavy metal pollution events such as "cadmium rice", "blood lead" and "arsenic toxin" occurred frequently, which arouse people's great attention to it (Zhai et al., 2019; Hwang et al., 2019; Jain and Chandramani, 2018). Cadmium is a non-essential element for plant and human growth and one of the most toxic heavy metal elements (Sun et al., 2018).

Into the soil of the $\mathrm{Cd}$ (II) in a dynamic balance of adsorption and desorption, because of the heterogeneity of soil surface, there are different adsorption sites, including the binding energy of the high level and the low level. When the lower initial concentration of exogenous Cd (II), Cd (II) was first adsorbed on the binding energy of high level, giving priority to with obligate adsorption, adsorption speed faster, with the increase of initial concentration of Cd (II), obligate adsorption points gradually reduced, Cd (II) from predominantly obligate adsorption to give priority to with non-obligate adsorption, adsorption speed slower (Naiya et al., 2009). In general, temperature, soil type, organic matter, and clay minerals content type and amount, iron, manganese oxide, and calcium carbonate content are different, all can lead to different adsorption quantity of Cd (II) in soil, which greatly influenced by the pH (Liao, 2006; Sprynskyy et al., 2011). The adsorption capacity of heavy metal increases with the increase of $\mathrm{pH}$ value. Wang (Wang, 2012) investigated 18 kinds of typical soil in China, the study found the temperature rising in different soil types on $\mathrm{Cd}$ (II) adsorption capacity increased, but instead of desorption quantity was reduced, soil showed that under the condition of high temperature on Cd (II) stronger adsorption ability, and difficult to desorption. A study conducted by Yuan et al. (2019) claimed that the addition of organic matter can effectively immobilize soil Cd (II) at an appropriate concentration in the environment by stimulating the reduction of primary oxidation components of soil by microorganisms. Li et al. (2007) studied Cd (II) in the black soil, yellow-brown soil, yellow soil, red soil of different graded composition of cadmium adsorption effect, four kinds of soil adsorption Cd (II) capacities were in the form of clay $>$ silt $>$ fine sand $>$ coarse sand.

For adsorption of soil heavy metal and saline-alkaline soil restoration work have been reported more. In this study, we objected of the adsorption characteristics of $\mathrm{Cd}$ (II) in Jilin province three different saline-alkaline soil samples and the influence of adding biochar adsorption behavior for Cd (II), starting from the physical and chemical properties of saline-alkaline soil itself directly, to study the adsorption of Cd (II) in soil potential, in order to fully understand the degree of saline-alkaline of soil $\mathrm{Cd}$ (II) adsorption ability. Moreover, we studied the different $\mathrm{pH}$ values and the addition of biochar to saline-alkaline soil adsorption of $\mathrm{Cd}$ (II), to seek effective measures to control soil Cd (II) environment behavior, as well as to provide a theoretical basis for Cd (II) saline-alkaline soil restoration.

\section{Materials and methods}

\section{Test samples}

Sampling sites were located in $\mathrm{Da}$ 'an Lesheng township west $10 \mathrm{~km}$ shop in Jilin province, China $\left(45^{\circ} 33^{\prime} 4^{\prime \prime} \mathrm{N}, 123^{\circ} 45^{\prime} 58^{\prime \prime} \mathrm{E}\right)$. Because of terrain elevation difference and different slope direction, this place formed a natural depression "Disk depressions", which subtle differences in the terrain height caused soil surface salinity distribution unevenly, formed a different saline-alkaline degree of soil in the micro-region (Wang et al., 2009; Martin et al., 2019). The sampling terrain was shown in Figure 1. In the "Disc 
depression" in the micro-region, sampling sites were taken the surface soil in $0-20 \mathrm{~cm}$ arranged according to different contour lines and removed off the sundries such as gravel, root plants and straw from the soil samples, then air-dried through a 100-mesh sieve, and stored in self-sealing bags for later use.

With the increase of terrain height in different micro-regions, $\mathrm{pH}$ value of soil, conductivity and total salt content gradually increased. Three test samples were determined in three separate contour lines, which were respectively: mildly salinealkaline soil, moderately saline-alkaline soil, and severely saline-alkaline soil. The basic physical and chemical properties of the soil were given in Table 1 and the water-soluble salt content in Table 2.

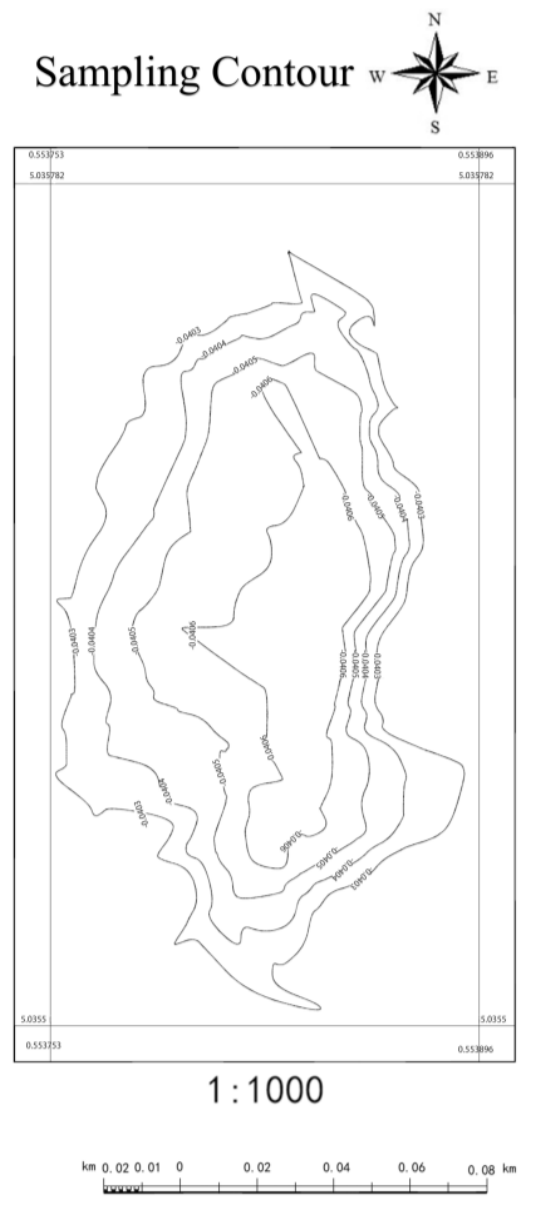

Figure 1. Sampling point topographic map

Table 1. Basic physical and chemical properties of the tested soil

\begin{tabular}{|c|c|c|c|c|c|c|c|c|c|}
\hline \multirow{2}{*}{ Soil type } & \multirow{2}{*}{ pH } & \multirow{2}{*}{$\begin{array}{c}\text { Exchangeable Na } \\
\left(\mathrm{mol} \cdot \mathrm{kg}^{-1}\right)\end{array}$} & \multirow{2}{*}{$\begin{array}{c}\text { Conductivity } \\
(\mathrm{S} / \mathrm{m})\end{array}$} & \multirow{2}{*}{$\begin{array}{c}\text { Organic matters } \\
\left(\mathrm{g} \cdot \mathrm{kg}^{-1}\right)\end{array}$} & \multirow{2}{*}{$\begin{array}{c}\text { CEC } \\
\left(\mathrm{mol}^{\prime} \mathrm{kg}^{-1}\right)\end{array}$} & \multirow{2}{*}{$\begin{array}{c}\text { Cd (II) } \\
\text { concentration } \\
\left(\mathbf{m g} \cdot \mathbf{k g}^{-1}\right)\end{array}$} & \multicolumn{3}{|c|}{ Composition (\%) } \\
\hline & & & & & & & Clay & Silt & Sand \\
\hline $\begin{array}{l}\text { Mildly saline- } \\
\text { alkaline soil }\end{array}$ & 8.68 & 0.34 & 17.8 & 1.05 & 14.2 & 0.07 & 29.1 & 21.3 & 49.6 \\
\hline $\begin{array}{l}\text { Moderately saline- } \\
\text { alkaline soil }\end{array}$ & 9.42 & 0.57 & 19.6 & 1.34 & 18.6 & 0.08 & 29.7 & 32.1 & 38.2 \\
\hline $\begin{array}{l}\text { Severely saline- } \\
\text { alkaline soil }\end{array}$ & 11.08 & 0.75 & 25.3 & 1.91 & 21.5 & 0.08 & 34.8 & 39.7 & 25.5 \\
\hline
\end{tabular}


Table 2. Water soluble salt content in the tested soil $(\mathrm{g} / \mathrm{kg})$

\begin{tabular}{c|c|c|c|c|c|c|c|c}
\hline Soil type & $\mathbf{N a}^{+}$ & $\mathbf{K}^{+}$ & $\mathbf{C a}^{2+}$ & $\mathbf{M g}^{2+}$ & $\mathbf{C O}_{3}{ }^{-2}$ & $\mathbf{H C O}_{3}$ & $\mathbf{C l}^{-}$ & $\mathbf{S O}^{2-}$ \\
\hline Mildly saline-alkaline soil & 5.7 & 1.17 & 0.09 & 0.15 & 3.57 & 0.32 & 0.09 & 0.29 \\
Moderately saline-alkaline soil & 7.01 & 2.23 & 0.21 & 0.21 & 8.72 & 1.21 & 0.73 & 0.31 \\
Severely saline-alkaline soil & 15.02 & 3.18 & 0.36 & 0.51 & 7.34 & 1.63 & 1.04 & 0.36 \\
\hline
\end{tabular}

\section{Test design}

\section{Different saline-alkaline soil of Cd (II) adsorption kinetics test}

Took the sample $(0.5000 \pm 0.0005) \mathrm{g}$ in a centrifuge tube, added $25 \mathrm{~mL} \mathrm{Cd}$ (II) solution with concentration of $20 \mathrm{mg} \cdot \mathrm{L}^{-1}$ in the background solution of $0.01 \mathrm{~mol} \cdot \mathrm{L}^{-1}$ $\mathrm{NaNO}_{3}$ (Analytical purity), oscillated the sample for 1, 5, 10, 20, 30, 60, 120, 240, 360, 480, 600, $1440 \mathrm{~min}$, centrifuged for $10 \mathrm{~min}$ in a high-speed tabletop centrifuge of $10000 \mathrm{r} \cdot \mathrm{min}^{-1}$ (TDL-40B from Agilent Company in America), and then filtered. The concentration of $\mathrm{Cd}$ (II) in the supernatant was determined by the atomic absorption spectrophotometer (TAS-990 from Pursee Company in Beijing, China).

\section{Different saline-alkaline soil of Cd (II) adsorption isothermal test}

The sample $(0.5000 \pm 0.0005) \mathrm{g}$ was placed in a centrifuge tube, and $25 \mathrm{~mL} \mathrm{Cd}$ (II) solution with a concentration gradient of $10,20,30,50,100,150,200$ and $300 \mathrm{mg} \cdot \mathrm{L}^{-1}$ solutions were added with $0.01 \mathrm{~mol} \cdot \mathrm{L}^{-1} \mathrm{NaNO}_{3}$ as the background solution. The adsorption isotherm was determined by oscillating for $24 \mathrm{~h}$ at a constant temperature of $25^{\circ} \mathrm{C}$ (adsorption kinetics test confirmed that adsorption saturation had been reached for $24 \mathrm{~h}$ ). Repeat isothermal adsorption experiments were performed at temperatures of $15^{\circ} \mathrm{C}, 25^{\circ} \mathrm{C}$ and $35^{\circ} \mathrm{C}$, to study the effect of different temperatures on adsorption.

\section{Different $\mathrm{pH}$ and added biochar in saline-alkaline soil of Cd (II) absorption test}

The $\mathrm{pH}$ of the background solution was adjusted to 3.0, 5.0, 7.0, 9.0 and 11.0 with $1 \mathrm{~mol} \cdot \mathrm{L}^{-1} \mathrm{HCl}$ (Analytical purity) and $\mathrm{NaOH}$ (Analytical purity) solution. Added $0.00 \%$, $0.5 \%, 1 \%, 3 \%, 5 \%$ and $10 \%$ biochar [The tested biochar is made from corn stalks that have passed through a 20 mesh sieve. Pyrolyzed in a muffle furnace (Jiangsu Zhengfei Electric Furnace Factory) at $500{ }^{\circ} \mathrm{C}$ for $3 \mathrm{~h}$, after the end of pyrolysis, cooled to room temperature, passed through a 100 mesh sieve)]. Kept constant temperature and shocked for $24 \mathrm{~h}$ at $25^{\circ} \mathrm{C}$, and determined the concentration of $\mathrm{Cd}$ (II) in the supernatant.

\section{Data processing and calculation}

All experiments were repeated three times. The obtained data were calculated and plotted by Excel 2010 and Origin 8.5.

\section{The adsorption capacity of the solution}

Equation 1 was used to measure the adsorption capacity of the solution.

$$
q_{t}=\frac{\left(c_{0}-c_{t}\right) V}{m}
$$


where $q_{t}$ is the adsorption amount of $\mathrm{Cd}$ (II) $\left(\mathrm{mg} \cdot \mathrm{kg}^{-1}\right)$; $C_{0}$ is the initial concentration of $\mathrm{Cd}$ (II) $\left(\mathrm{mg} \cdot \mathrm{L}^{-1}\right) . C_{t}$ is used to measure the concentration of Cd (II) in the supernatant $\left(\mathrm{mg} \cdot \mathrm{L}^{-1}\right) . V$ is the volume of $\mathrm{Cd}$ (II) solution $(\mathrm{mL}) ; m$ is the mass of soil or soil plus biochar $(\mathrm{g})$.

\section{Kinetic model}

Pseudo-first-order kinetic model:

$$
q_{t}=Q_{\theta_{1} 1}\left(1-e^{-k_{1} t}\right)
$$

Pseudo-second-order kinetics model:

$$
q_{t}=\frac{Q_{E, 2}^{2} k_{2} t}{1+Q_{B_{2}} k_{2} t}(\text { Nonlinear form) }
$$

Elovich model:

$$
q_{t}=a+b \ln t
$$

where $q_{t}$ is the adsorption amount of Cd (II) at time $t\left(\mathrm{mg} \cdot \mathrm{g}^{-1}\right)$; In Equation 2, $Q_{e, l}$ and $k_{1}$ represent the adsorption equilibrium quantity $\left(\mathrm{mg} \cdot \mathrm{g}^{-1}\right)$ and the adsorption rate constant $\left(\mathrm{g} \cdot \mathrm{mg}^{-1} \cdot \mathrm{min}^{-1}\right)$ of Cd (II) respectively. In Equation 3, $Q_{e, 2}^{2}$ and $k_{2}$ represent the adsorption equilibrium quantity $\left(\mathrm{mg} \cdot \mathrm{g}^{-1}\right)$ and adsorption rate constant $\left(\mathrm{g} \cdot \mathrm{mg}^{-1} \cdot \mathrm{min}^{-1}\right)$ of Cd (II) respectively. In Equation 4, $a$ is the adsorption constant related to the maximum adsorption capacity, and $b$ is the adsorption rate coefficient, which is a measure of how fast the reaction rate decreases with the extension of time.

\section{Isotherm model}

Langmuir model:

$$
q_{B}=\frac{K_{L} q_{m} C_{t}}{1+K_{L} c_{t}}(\text { Nonlinear form })
$$

Freundlich model:

$$
q_{e}=K_{F} c_{t}^{1 / n}(\text { Nonlinear form })
$$

where $q_{e}$ is the equilibrium adsorption amount of $\mathrm{Cd}$ (II) $\left(\mathrm{mg} \cdot \mathrm{g}^{-1}\right) ; q_{m}$ and $K_{L}$ is Langmuir model parameters, representing the maximum adsorption capacity $\left(\mathrm{mg} \cdot \mathrm{g}^{-1}\right)$ and adsorption energy $\left(\mathrm{L} \cdot \mathrm{mg}^{-1}\right)$ of Cd (II), respectively. $K_{F}$ and $n$ are Freundlich model parameters, representing $\mathrm{Cd}$ (II) adsorption capacity $\left(\mathrm{mg} \cdot \mathrm{g}^{-1} \cdot\left(\mathrm{mg} \cdot \mathrm{L}^{-1}\right)^{-1 / \mathrm{n}}\right)$ and adsorption strength, respectively.

The thermodynamic model parameter calculation

$$
K_{d}=\frac{\left(c_{0}-c_{t}\right) V}{c_{t} m}
$$




$$
\begin{gathered}
\ln K_{d}=\frac{\Delta S^{\circ}}{R}-\frac{\Delta H^{s}}{R T} \\
\Delta \mathrm{G}^{\circ}=\Delta \mathrm{H}^{\circ}-\mathrm{T} \Delta \mathrm{S}^{\mathrm{a}}
\end{gathered}
$$

where $\Delta G^{\circ}$ is the standard free energy change $\left(\mathrm{kJ} \cdot \mathrm{mol}^{-1}\right), \Delta H^{\circ}$ is the standard enthalpy change $\left(\mathrm{kJ} \cdot \mathrm{mol}^{-1}\right)$ and $\Delta S^{\circ}$ is the standard entropy change $\left(\mathrm{kJ} \cdot \mathrm{mol}^{-1}\right), K_{d}$ is the thermodynamic equilibrium constant $\left(\mathrm{mL} \cdot \mathrm{g}^{-1}\right), R$ is the ideal gas constant $R$ $\left(8.314 \mathrm{~J} \cdot \mathrm{mol} \cdot \mathrm{K}^{-1}\right), T$ is the temperature $(\mathrm{K})$, the value of $\Delta H^{\circ}$ and $\Delta S^{\circ}$ are the slope and intercept of $\ln K_{d}-T^{-1}$ diagram, respectively.

\section{Correlation coefficient significance test}

Find the correlation coefficient significance test table, and then determine the degree of freedom (n-2), where $n$ represents the number of samples; find the value corresponding to $a 0.001, a 0.005, a 0.01$ in the test table, and the fit will be obtained. The correlation coefficient $r$ value is compared with $a$ to determine the level of significance. For example, if $r>a$, it is extremely significant.

\section{Results and discussion}

\section{Study on adsorption kinetics of Cd (II) in different saline-alkaline soils}

The initial concentration of $\mathrm{Cd}$ (II) was $20 \mathrm{mg} \cdot \mathrm{L}^{-1}$, and the adsorption capacity of $\mathrm{Cd}$ (II) in mildly, moderately and severely saline-alkaline soil changed with time, as shown in Figure 2.

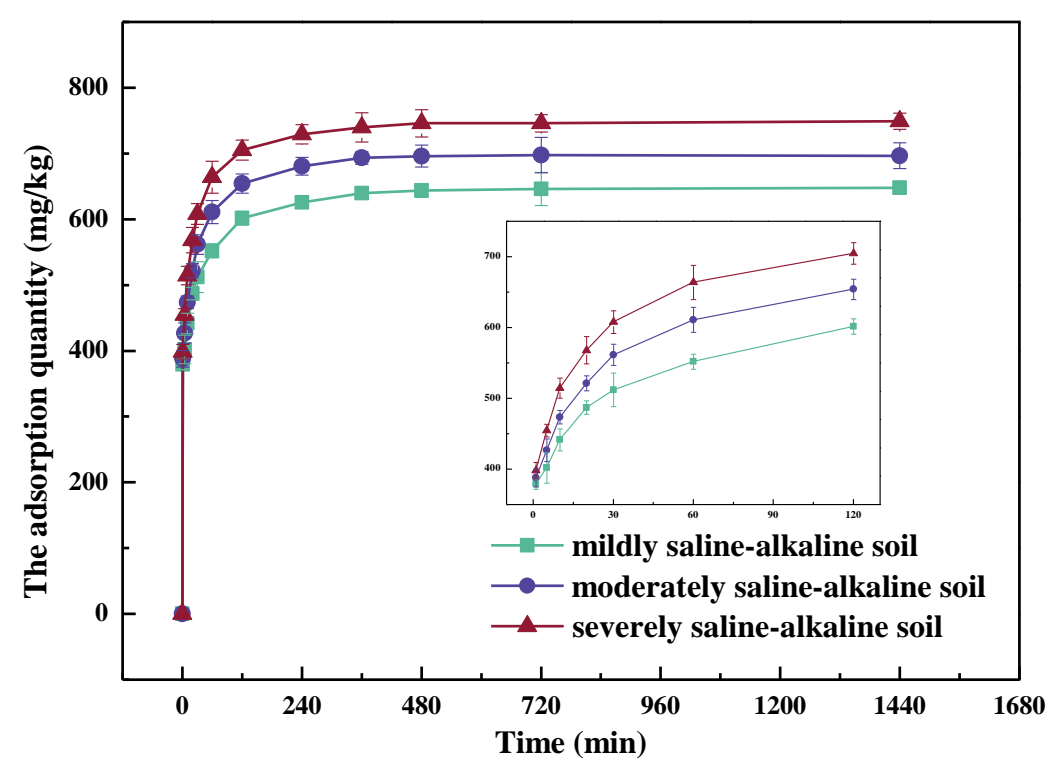

Figure 2. Adsorption kinetics of Cd (II) in sample soil with three different saline-alkaline stresses

The adsorption process of Cd (II) in the three tested soil samples can be divided into three stages: fast adsorption, slow adsorption, and equilibrium adsorption (Figure 2). Within $0 \sim 120$ min was the rapid adsorption stage, the adsorption capacity of mildly, 
moderately and severely saline-alkaline soil accounted for $92.840 \%, 93.941 \%$ and $94.126 \%$ of the total adsorption capacity, respectively. The adsorption rate of Cd (II) in the three tested samples was: severely saline-alkaline soil > moderately saline-alkaline soil $>$ mildly saline-alkaline soil. At the initial stage of adsorption, there were many adsorption sites on the soil surface, and the adsorption rate was fast.

When the adsorption sites on the soil surface reached saturation, Cd (II) was adsorbed to the internal sites of the soil, and the adsorption rate slowed down up to a threshold (Tsang et al., 2007; Arias et al., 2005). These interactions including different interactions: first, surface complexation reactions which are basically inner-sphere surface complexes of the Cd (II) and the respective surface functional groups; second, electrostatic interactions where the $\mathrm{Cd}$ (II) form outer-sphere, complexes at a certain distance from the surface; third, hydrophobic expulsion of metal complexes containing highly nonpolar organic solutes, and fourth, surfactant adsorption of metalpolyelectrolyte complexes due to reduced surface tension (Bradl, 2004).

The pseudo-first-order kinetic model is a single adsorption process, while the pseudo-second-order kinetic model usually describes the chemical adsorption process, including electron sharing and transfer (covalent bond and ion exchange) between adsorbents and adsorbents (Ho, 2006). Elovich tends to describe a series of reaction mechanisms such as solute diffusion at the solid-liquid interface. The adsorption kinetics of Cd (II) in mildly, moderately and severely saline-alkaline soils were fitted by the pseudo-first-order kinetic model, pseudo-second-order kinetic model, and Elovich model. The fitting results were given in Table 3.

Table 3. Adsorption kinetics fitting parameters of $C d$ (II) in soils with three different salinealkaline stresses

\begin{tabular}{c|c|c|c|c|c|c|c|c|c}
\hline \multirow{2}{*}{ Soil type } & \multicolumn{3}{|c|}{$\begin{array}{c}\text { Pseudo-first-order kinetic } \\
\text { model }\end{array}$} & \multicolumn{2}{c|}{$\begin{array}{c}\text { Pseudo-second-order } \\
\text { kinetic model }\end{array}$} & \multicolumn{3}{c}{ Elovich model } \\
\cline { 2 - 9 } & $\boldsymbol{Q}_{e .1}$ & $\boldsymbol{k}_{\boldsymbol{1}}$ & $\boldsymbol{r}$ & $\boldsymbol{Q}_{\text {e.2 }}$ & $\boldsymbol{K}_{\boldsymbol{2}}$ & $\boldsymbol{r}$ & $\boldsymbol{a}$ & $\boldsymbol{b}$ & $\boldsymbol{r}$ \\
\hline $\begin{array}{c}\text { Mildly saline- } \\
\text { alkaline soil }\end{array}$ & 548.225 & 103.094 & $0.828 * *$ & 594.169 & 0.001 & $0.931 * *$ & 360.163 & 44.615 & $0.993^{* *}$ \\
$\begin{array}{c}\text { Moderately saline- } \\
\text { alkaline soil } \\
\begin{array}{c}\text { Severely saline- } \\
\text { alkaline soil }\end{array}\end{array}$ & 591.688 & 111.385 & $0.815 * *$ & 649.824 & 0.001 & $0.938 * *$ & 379.229 & 50.402 & $0.992^{* *}$ \\
\hline
\end{tabular}

**Highly significant correlation $(n=12, r 0.05=0.576, r 0.01=0.708)$

It can be seen from Table 3 that the fitting effect of pseudo-first-order dynamic model was the worst, and the correlation coefficient $r$ value was the minimum of 0.810 0.828 . The Elovich model had the largest correlation coefficient $r$ value, which was $0.931,0.938$ and 0.948 , respectively. However, according to the fitting model, the equilibrium adsorption capacity of mildly, moderately and severely saline-alkaline soil to $\mathrm{Cd}$ (II) was $360.163,379.229$ and $403.729 \mathrm{mg} \cdot \mathrm{kg}^{-1}$, respectively, which were significantly different from the experimental values of 648.000, 696.500 and $749.000 \mathrm{mg} \cdot \mathrm{kg}^{-1}$, respectively. The pseudo-second-order kinetic model could better describe the Cd (II) adsorption characteristics of the three sample soil, and the $r$ values of the correlation coefficients are $0.931,0.938$ and 0.948 , respectively. The fitted equilibrium adsorption capacities of $594.169,649.824$ and $702.594 \mathrm{mg} \cdot \mathrm{kg}^{-1}$ were closed 
to the experimental values. The pseudo-second-order kinetic model was usually used to describe the chemical adsorption process, and it was concluded that the adsorption of $\mathrm{Cd}$ (II) in the three kinds of soil was dominated by chemical adsorption (Rao et al., 2010).

\section{Adsorption isotherms of Cd (II) in different saline-alkaline soils}

The Cd (II) solutions of $0,20,30,50,100,150,200$, and $300 \mathrm{mg} \cdot \mathrm{L}^{-1}$ were added to the mildly, moderately, and severely saline-alkaline soil, and were oscillated for $24 \mathrm{~h}$ at a constant temperature of $25{ }^{\circ} \mathrm{C}$ to determine the adsorption capacity of $\mathrm{Cd}$ (II), as shown in Figure 3.

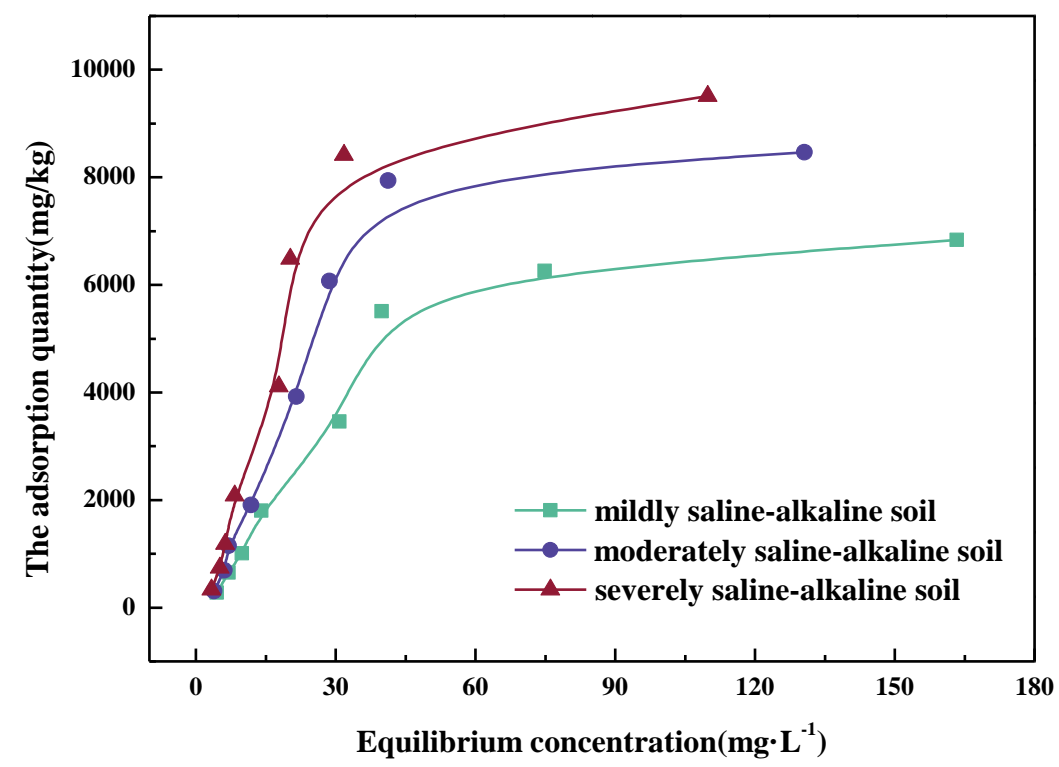

Figure 3. Adsorption isotherms of Cd (II) in sample soil with three different saline-alkaline stresses

It can be seen from Figure 3, with the increasing of Cd (II) concentration, three kinds of soil on Cd (II) adsorption quantity also promoted, Table 1 showed that three of the $\mathrm{pH}$ value of the soil samples were $8.68,9.42,11.08$, respectively, all belong to salinealkaline soil. Due to Cd (II) hydroxide insoluble in water, after the Cd (II) into the soil and water mixture, $\mathrm{Cd}$ (II) with $\mathrm{OH}^{-}$formed hydrated metal ions in the solution or hydroxide precipitation, the model was as follows:

$$
\mathrm{Cd}^{2+}+2 \mathrm{H}_{2} \mathrm{O}=\mathrm{Cd}(\mathrm{OH})_{2} \downarrow+2 \mathrm{H}^{+}
$$

With the increasing concentration of Cd (II) ions, Eq.10 reaction continued to the right, and the hydroxide precipitation of Cd (II) continues to be generated (Wang et al., 2019), which showed that the adsorption capacity of soil to Cd (II) gradually increased. At the same concentration of Cd (II), the adsorption capacity of Cd (II) in the three tested soil was: severely saline-alkaline soil $>$ moderately saline-alkaline soil $>$ mildly salinealkaline soil. When the concentration of Cd (II) in the equilibrium solution was 0-50 $\mathrm{mg} \cdot \mathrm{L}^{-1}$, the slope of the adsorption isotherm was large, that meaning the adsorbed amount of $\mathrm{Cd}$ (II) in the three soils increased rapidly with the increasing of $\mathrm{Cd}$ (II) concentration. 
When the equilibrium concentration of Cd (II) was greater than $50 \mathrm{mg} \cdot \mathrm{L}^{-1}$, the slope of the adsorption isothermal curve gradually decreased, and the maximum adsorption capacity of the three kinds of soil reached 1798.803, 1909.739 and $2083.779 \mathrm{mg} \cdot \mathrm{kg}^{-1}$, respectively. That was, the change range of the adsorption capacity of $\mathrm{Cd}$ (II) reduced until it finally reached adsorption saturation. Since obligate adsorption was dominant in the region with low adsorption capacity, most Cd (II) may be adsorbed at high energy sites, and the adsorption speed was fast. After reaching a certain saturation, obligate adsorption sites gradually decreased, and Cd (II) changed from obligate adsorption to non-obligate adsorption, with a slower adsorption speed (Hu et al., 2010).

The adsorption isotherms of mildly, moderately and severely saline-alkaline soil to Cd (II) was fitted by Langmuir and Freundlich models, and the fitting parameters were shown in Table 4.

Table 4. Adsorption isotherm parameters of Cd (II) on three different soils with salinealkaline stress

\begin{tabular}{c|c|c|c|c|c|c}
\hline \multirow{2}{*}{ Soil type } & \multicolumn{3}{|c|}{ Langmuir parameter } & \multicolumn{3}{c}{ Freundlich parameter } \\
\cline { 2 - 7 } & $\boldsymbol{q}_{\boldsymbol{m}}$ & $\boldsymbol{K}_{\boldsymbol{L}}$ & $\boldsymbol{r}$ & $\boldsymbol{n}$ & $\boldsymbol{K}_{\boldsymbol{F}}$ & $\boldsymbol{r}$ \\
\hline Mildly saline-alkaline soil & 9573.048 & 0.021 & $0.963 * *$ & 553.913 & 1.924 & $0.907 * *$ \\
Moderately saline-alkaline soil & 12046.321 & 0.026 & $0.941^{* *}$ & 787.720 & 1.940 & $0.907 * *$ \\
Severely saline-alkaline soil & 13248.917 & 0.032 & $0.938^{* *}$ & 958.990 & 1.947 & $0.867 * *$ \\
\hline
\end{tabular}

**Highly significant correlation $(n=8, r 0.05=0.707, r 0.01=0.834)$

As can be seen from Table 4, Langmuir model was used to better fit the adsorption process of Cd (II) of the three soil samples, and the correlation coefficient $r$ values were $0.963,0.941$ and 0.938 respectively. The $K_{L}$ value in the Langmuir model represents the adsorption affinity constant (Xie et al., 2019), and the larger $K_{L}$ was, the better the adsorption effect. In the adsorption process of Cd (II) in the three soils, $K_{L}$ values were $0.021,0.026$ and 0.032 , respectively, all of which were greater than zero, indicating that the adsorption reaction could be spontaneous at room temperature. The $K_{F}$ value in the Freundlich model represents the adsorption capacity of Cd (II). The higher the $K_{F}$ value is, the stronger the adsorption capacity is. The $K_{F}$ values in the three kinds of salinealkaline soil were 553.913, 787.702 and 958.990, respectively, which were consistent with the conclusion obtained in the Langmuir model that was: severely saline-alkaline soil > moderately saline-alkaline soil > mildly saline-alkaline soil. The $n$ value in the Freundlich model can represent the adsorption strength, and the larger $n$ value is, the stronger the adsorption strength will be (Ma et al., 2015). The $n$ values of the three kinds of soils were 553.913, 787.720 and 958.990, respectively, indicating that the severely saline-alkaline soil had more and more complex energy adsorption sites.

\section{Study on adsorption thermodynamics of Cd (II) in different saline-alkaline soil}

Within the test temperature range $\left(15,25,35^{\circ} \mathrm{C}\right)$, thermodynamic fitting parameters of Cd (II) adsorption in mildly, moderately and severely saline-alkaline soil was shown in Table 5.

It can be seen from Table 5 that, with the increasing of temperature, the adsorption capacity of three kinds of soil to Cd (II) gradually increased, and the adsorption capacity of severely saline-alkaline soil was the largest. The Langmuir model had the best fitting 
effect on Cd (II) adsorption in the three soil, and the correlation coefficient $r$ was greater than 0.915. The higher the temperature was, the more favorable it was for $\mathrm{Cd}$ (II) adsorbed on the soil surface to diffuse into the particles, for the transformation of the outer complex to inner complex, and for the transformation of thermodynamically unstable combination to stable combination (Xie et al., 2019). According to the different temperature adsorption capacity, can calculate the 3 different saline-alkaline soil adsorption thermodynamic parameters of $\Delta H^{\circ}, \Delta G^{\circ}$ and $\Delta S^{\circ}, \Delta G^{\circ}$ on behalf of the reaction is a spontaneous or spontaneous reaction, $\Delta H^{\circ}$ on behalf of the reaction is an endothermic or exothermic reaction, $\Delta S^{\circ}$ representative is an orderly or disorderly reaction, the thermodynamic parameters as shown in Table 6.

Table 5. Thermodynamic models for adsorption of Cd (II) at different temperatures

\begin{tabular}{c|c|c|c|c|c|c|c}
\hline \multirow{2}{*}{ Soil type } & Temperature T & \multicolumn{3}{|c|}{ Langmuir parameter } & \multicolumn{2}{c}{ Freundlich parameter } \\
\cline { 3 - 7 }$\left({ }^{\circ} \mathbf{C}\right)$ & $\boldsymbol{q}_{\boldsymbol{m}}$ & $\boldsymbol{K}_{\boldsymbol{L}}$ & $\boldsymbol{r}$ & $\boldsymbol{n}$ & $\boldsymbol{K}_{\boldsymbol{F}}$ & $\boldsymbol{r}$ \\
\hline \multirow{2}{*}{ Mildly saline- } & 15 & 9427.858 & 0.018 & $0.960 * *$ & 475.065 & 1.860 & $0.909 * *$ \\
alkaline soil & 25 & 9573.048 & 0.021 & $0.963 * *$ & 553.913 & 1.924 & $0.907 * *$ \\
& 35 & 13820.899 & 0.018 & $0.915^{* *}$ & 594.036 & 1.711 & $0.863 * *$ \\
\hline \multirow{2}{*}{ Moderately saline- } & 15 & 10195.745 & 0.023 & $0.955^{* *}$ & 647.129 & 1.963 & $0.894 * *$ \\
alkaline soil & 25 & 12046.321 & 0.026 & $0.941^{* *}$ & 787.720 & 1.940 & $0.870^{* *}$ \\
& 35 & 14591.058 & 0.023 & $0.970^{* *}$ & 743.431 & 1.752 & $1.323^{* *}$ \\
\hline \multirow{2}{*}{ Severely saline- } & 15 & 10568.180 & 0.029 & $0.956 * *$ & 802.741 & 2.054 & $0.887 * *$ \\
alkaline soil & 25 & 13248.917 & 0.032 & $0.938^{* *}$ & 958.990 & 1.947 & $0.867 * *$ \\
& 35 & 14799.801 & 0.032 & $0.937 * *$ & 978.863 & 1.846 & $0.874 * *$ \\
\hline
\end{tabular}

**Highly significant correlation $(n=8, r 0.05=0.707, r 0.01=0.834)$

Table 6. Thermodynamic parameters of $C d(I I)$ in three sample soil

\begin{tabular}{|c|c|c|c|c|}
\hline Soil type & $\begin{array}{c}\text { Temperature } \mathbf{T} \\
\left({ }^{\circ} \mathbf{C}\right)\end{array}$ & $\Delta G\left(\mathbf{k J} \cdot \mathbf{m o l}^{-1}\right)$ & $\Delta H\left(\mathbf{k J} \cdot \mathrm{mol}^{-1}\right)$ & $\Delta S\left(\mathbf{J} \cdot \mathbf{m o l}^{-1} \cdot \mathbf{K}^{-1}\right)$ \\
\hline \multirow{3}{*}{ Mildly saline-alkaline soil } & 15 & -21.773 & \multirow{3}{*}{9.554} & \multirow{3}{*}{0.109} \\
\hline & 25 & -23.404 & & \\
\hline & 35 & -25.036 & & \\
\hline \multirow{3}{*}{ Moderately saline-alkaline soil } & 15 & -22.084 & \multirow{3}{*}{9.080} & \multirow{3}{*}{0.108} \\
\hline & 25 & -23.707 & & \\
\hline & 35 & -25.330 & & \\
\hline \multirow{3}{*}{ Severely saline-alkaline soil } & 15 & -22.223 & \multirow{3}{*}{8.588} & \multirow{3}{*}{0.107} \\
\hline & 25 & -23.828 & & \\
\hline & 35 & -25.433 & & \\
\hline
\end{tabular}

It can be seen from Table 6 , experimental design temperature $15^{\circ} \mathrm{C}, 25^{\circ} \mathrm{C}$ and $35^{\circ} \mathrm{C}$ range, three kinds of soil $\Delta G^{\circ}$ values are less than zero, the adsorption process is spontaneous, and with the increasing of temperature, $\Delta G^{\circ}$ gradually became smaller, the higher the temperature of three kinds of soil Cd (II) adsorption spontaneous stronger; Three kinds of soil reaction enthalpy changing $\Delta H^{\circ}$ were positive, suggests that Cd (II) in three kinds of soil adsorption process was endothermic reaction; $\Delta S^{\circ}$ greater than zero, which indicated that adsorption process was disorderly. 


\section{Effect of pH on Cd (II) adsorption in soil}

$\mathrm{pH}$ is one of the most important factors affecting soil adsorption and desorption of Cd (II) (Li et al., 2013). In the pH range of the test (3.0 11.0), the adsorption of Cd (II) by mildly, moderately and severely saline-alkaline soil was shown in Figure 4.

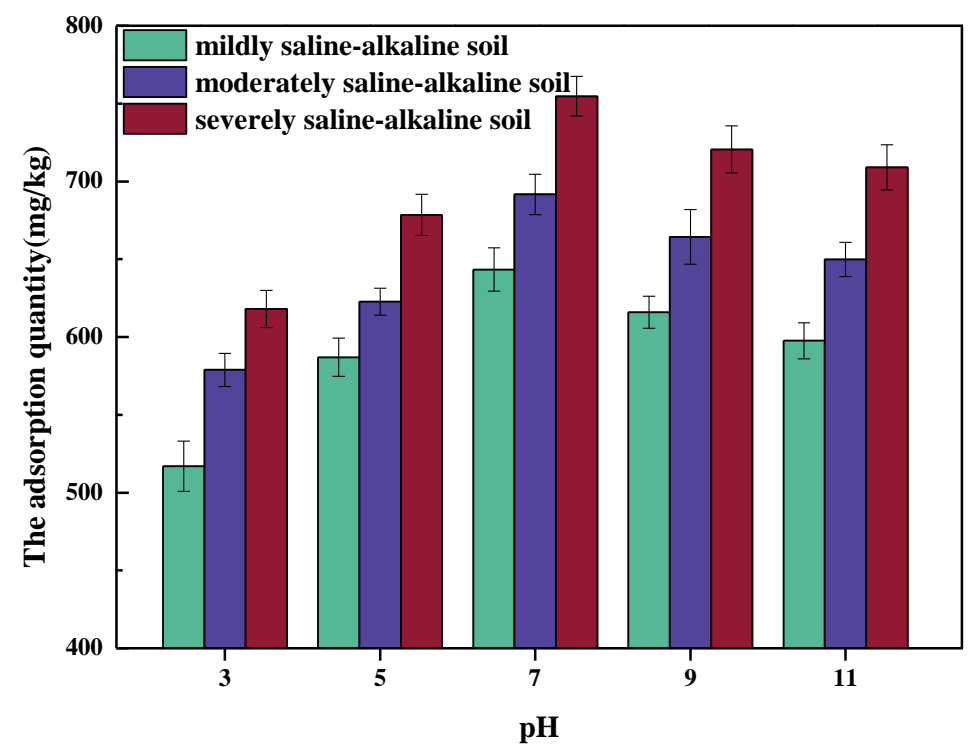

Figure 4. Effect of different $p H$ values on adsorption of Cd (II) in three sample soil

It can be seen from Figure 4 that, with the initial $\mathrm{pH}$ of the background adsorption solution increasing, the adsorption capacity of the three tested soil to $\mathrm{Cd}$ (II) first increased and then decreased. When the $\mathrm{pH}$ of the background solution was 7.0, the adsorption capacity of $\mathrm{Cd}$ (II) was the largest, and the adsorption capacity of mildly, moderately and severely saline-alkaline soil to $\mathrm{Cd}$ (II) was $643.344 \mathrm{mg} \cdot \mathrm{kg}^{-1}$, $691.604 \mathrm{mg} \cdot \mathrm{kg}^{-1}$ and $754.728 \mathrm{mg} \cdot \mathrm{kg}^{-1}$, respectively. According to different adsorption mechanisms, $\mathrm{pH}$ may mainly affect $\mathrm{Cd}$ (II) adsorption by affecting the hydrolysis of $\mathrm{Cd}$ (II), the exchange between $\mathrm{Cd}$ (II) and $\mathrm{H}^{+}$, the type of adsorption surface, the adsorption surface charge, and the distribution coefficient of $\mathrm{Cd}$ (II) in the competitive system. There was a close relationship between $\mathrm{pH}$ and $\mathrm{Cd}$ (II) adsorption (Adhikari et al., 2003). When $\mathrm{pH}$ was low ( $\mathrm{pH}<7$ ), Cd (II) was subject to competitive adsorption of $\mathrm{H}^{+}$, with a small amount of adsorption (Xie et al., 2019). With the increase of initial pH, $\mathrm{OH}^{-}$increased, while the competitive adsorption of $\mathrm{H}^{+}$decreased and the adsorption of $\mathrm{Cd}$ (II) increased. At a high $\mathrm{pH}(\mathrm{pH}>7.0)$, there were a large number of surface functional groups such as sialons, inorganic hydroxyl groups and organic functional groups in the soil, which had negative charges with $\cdot \mathrm{OH}$ functional groups that broke the bond with the side and adsorbed with $\mathrm{Cd}$ (II) to form inner ring compounds, increasing the adsorption capacity of Cd (II) (Bradl, 2004).

\section{Effect of adding biochar on Cd (II) adsorption}

Biochar is a kind of porous, stable, carbonaceous and highly aromatic solid material obtained by pyrolysis of biomass under hypoxic or anaerobic conditions (Bashir et al., 2018), which has abundant functional groups. The effects of different biochar additions on Cd (II) adsorption capacity were shown in Figure 5. 


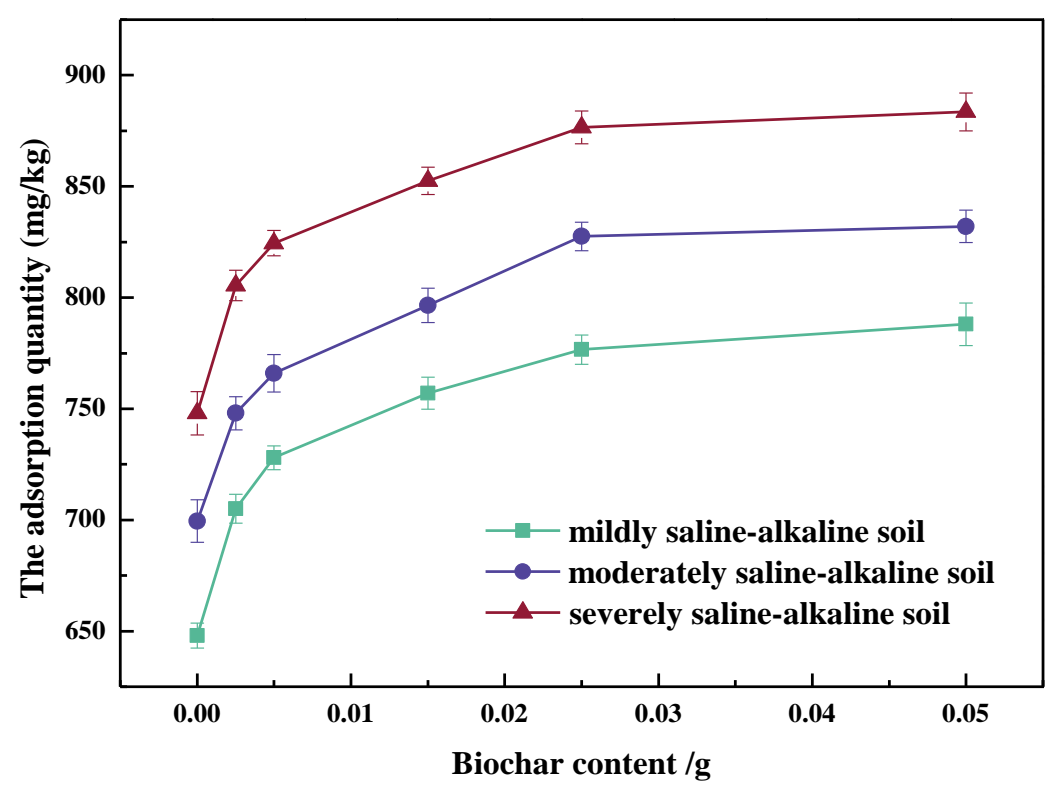

Figure 5. Relationship between the addition of biochar and $p H$ on adsorption of $C d$ (II) in three sample soil

It can be seen from Figure 5 that, with the increasing of biochar quantity, the adsorption capacity of mildly, moderately and severely saline-alkaline soil to Cd (II) gradually promoted. Due to the high content of organic matter in biochar, organic matter will react with Cd (II) to form stable complexes (Van Poucke et al., 2018). Surface complexation (inner- and outer-sphere) forms multiatom structures with unique metal-functional groups interactions, playing a predominant role in adsorption of heavy metals onto biochar. For example, heavy metals can be effectively bound by complexation with the carboxyl, phenolic and lactonic functional groups in biochar (Yang, 2019). The addition of biochar will increase the content of organic matter in the three kinds of soil, thus increasing the adsorption capacity of $\mathrm{Cd}$ (II). Among them, mildly saline-alkaline soil organic matter content was the lowest, so the increase of adsorption to Cd (II) was the largest, increasing by $21.605 \%$. The three soil tends to be saturated when the biochar content reaches a certain level.

\section{Conclusion}

This study examined the kinetics, adsorption isotherm of three different salinealkaline soil and two environmental parameters ( $\mathrm{pH}$ and addition of biochar) on $\mathrm{Cd}$ (II). Our results indicated the following: (1) The adsorption process of Cd (II) in three different saline-alkaline soil showed a trend of first fast and then slow. The pseudosecond-order kinetic model had a better fitting effect on adsorption kinetics. (2) The adsorption capacity of Cd (II) was: severely saline-alkaline soil > moderately salinealkaline soil $>$ mildly saline-alkaline soil and the adsorption capacity gradually increased with the increase of $\mathrm{Cd}$ (II) concentration. The Langmuir model fitted the adsorption isotherm well. (3) The adsorption of $\mathrm{Cd}$ (II) by saline-alkaline soil was a spontaneous, disordered and heat-absorbing reaction under the test temperature $15{ }^{\circ} \mathrm{C}$, $25^{\circ} \mathrm{C}$, and $35^{\circ} \mathrm{C}$.(4) $\mathrm{Cd}$ (II) adsorption effect of three soil was the best when $\mathrm{pH}$ was 7.0 between 3.0 and 11.0. (5) With the addition of biochar, the adsorption of $\mathrm{Cd}$ (II) in 
sample soil was increased, and which in mildly saline-alkaline soil promoted most significantly.

Our research demonstrated the importance of temperature, $\mathrm{pH}$ and organic matter in controlling the environmental behavior of cadmium in saline-alkaline soil. For example, $\mathrm{Cd}$ content in the same area saline-alkaline soil in summer will be lower than the same year winter, especially severely saline-alkaline soil areas, considering adding the biochar to increase soil organic matter content, reducing the content of $\mathrm{Cd}$ in soil, or adopting dripping irrigation technology to decrease the soil $\mathrm{pH}$ around the crop root, reducing $\mathrm{Cd}$ in the soil solution and thus reducing crop uptake $\mathrm{Cd}$. As a result, the investigation of saline-alkaline soil's characteristics will improve the saline-alkaline soil restoration technology which is a benefit to the environment and human health. Hence, there have two methods to recover saline-alkaline soil: one of it is to adjust $\mathrm{pH}$ in soil to neutral to remove heavy metal. In addition, its perspective to research environmentalfriendly adsorbents like biochar with more active sites, lower energy cost and could recycle wastes as stalks.

Acknowledgements. This work was supported by The National Key Research and Development Support Project (2016YFC0501201), Major Science and Technology Project of Jilin Province (20170204002SF), Natural Science Foundation of Jilin Province (20180101086JC), and Grant of National Natural Science Foundation (41877027).

\section{REFERENCES}

[1] Adhikari, T., Singh, M. V. (2003): Sorption characteristics of lead and cadmium in some soils of India. - Geoderma 114(1-2): 81-92.

[2] Arias, M., Perez-Novo, C., Osorio, F., López, E., Soto, B. (2005): Adsorption and desorption of copper and zinc in the surface layer of acid soils. - Journal of Colloid and Interface Science 288(1): 21-29.

[3] Ashraf, S., Ali, Q., Zahir, Z. A., Ashraf, S., Asghar, H. N. (2019): Phytoremediation: Environmentally sustainable way for reclamation of heavy metal polluted soils. Ecotoxicology and Environmental Safety 174: 714-727.

[4] Bashir, S., Zhu, J., Fu, Q. L., Hu, H. Q. (2018): Cadmium mobility, uptake and antioxidative response of water spinach (Ipomoea aquatic) under rice straw biochar, zeolite and rock phosphate as amendments. - Chemosphere 194: 579-587.

[5] Bradl, H. B. (2004): Adsorption of heavy metal ions on soils and soils constituents. Journal of Colloid \& Interface Science 277(1): 1-18.

[6] He, H. S., Wang, W. J., Zhu, H., Zu, Y. G., Zhang, Z. H., Guan, Y., Xu, H. N., Yu, X. Y. (2008): Influences of addition of different krilium in saline-sodic soil on the seed germination and growth of cabbage. - ActaEcologica Sinica 28(11): 5338-5346.

[7] He, L. Z., Zhong, H., Liu, G. X., Dai, Z. M., Brookes, P. C., Xu, J. M. (2019): Remediation of heavy metal contaminated soils by biochar: mechanisms, potential risks and applications in China. - Environmental Pollution 252: 846-855.

[8] Ho, Y. S. (2006): Review of second-order models for adsorption systems. - Journal of Hazardous Materials 3(136): 681-689.

[9] Hu, N. J., Luo, Y. M., Zhong, S. J. (2010): Adsorption of cadmium on typical soils in the Yangtze river delta and its relationship with organic matter, $\mathrm{pH}$ and temperature. Actasodiae sinica 44(2): 437-443.

[10] Hwang, Y. H., Hsiao, C. K., Lin, P. W. (2019): Globally temporal transitions of blood lead levels of preschool children across countries of different categories of Human Development Index. - Science of the Total Environment 659: 1395-1402. 
[11] Jain, N., Chandramani, S. (2018): Arsenic poisoning. An overview. - Indian Journal of Medical Specialities 9(3): 143-145.

[12] Li, C. L., Zhou, L. X. (2007): Study on the effects of different grain size components on cadmium adsorption behavior in several typical soils in China. - Journal of AgroEnvironmental Science 26(2): 516-520.

[13] Li, Y. M., Kang, C. L., Chen, W. W., Ming, L., Zhang, S., Guo, P. (2013): Thermodynamic characteristics and mechanisms of heavy metals adsorbed onto urban soil. - Chemical Research in Chinese Universities 29(1): 42-47.

[14] Liao, M. (2006): Effects of organic acids on adsorption of cadmium onto kaolinite, goethite and bayerite. - Pedosphere 16(2): 185-191.

[15] Ma, W., Zhang, M. M., Wang, R. Q., Xin, B. P., Guo, W., Dai, J. L. (2015): Mercury (II) Adsorption on three contrasting Chinese soils treated with two sources of dissolved organic matter: II. Spectroscopic characterization. - Soil and Sediment Contamination 24(6): 719-730.

[16] Martin, I., Matthias, W., Armin, K., Michael, M., Mark, R., Katy, M., Katharina, K., Emmanuel, F., Wolfgang, W., Moritz, B. (2019): Towards an understanding of the Cd (II) isotope fractionation during transfer from the soil to the cereal grain. - Environmental Pollution 244: 834-844.

[17] Naiya, T. K., Bhattacharya, A. K., Das, S. K. (2009): Adsorption of Cd (II) and Pb (II) from aqueous solutions on activated alumina. - Journal of Colloid and Interface Science 333(1): 14-26.

[18] Rao, K. S., Anand, S., Venkateswarlu, P. (2010): Adsorption of cadmium (II) ions from aqueous solution by Tectonagrandis L. F. (teak leaves powder). - Bio Resources 5(1): 438-454.

[19] Roberts, T. L. (2014): Cadmium and phosphorous fertilizers: the issues and the science. Procedia Engineering 83: 52-59.

[20] Saifullah, Dahlawi, S., Naeem, A., Rengel, Z., Naidu, R. (2018): Biochar application for the remediation of salt-affected soils: challenges and opportunities. - Science of the Total Environment 625: 320-335.

[21] Shi, S. H., Tian, L., Nasir, F., Bahadur, A., Batool, A., Luo, S. S., Yang, F., Wang, Z. C., Tian, C. J. (2018): The response of microbial communities and enzyme activities to amendments in saline-alkaline soils. - Applied Soil Ecology 135: 16-24.

[22] Sprynskyy, M., Kowalkowski, T., Tutu, H., Cozmuta, L. M., Cukrowska, E. A., Buszewski, B. (2011): The adsorption properties of agricultural and forest soils towards heavy metal ions (Ni, Cu, Zn, and Cd (II). - Journal of Soil Contamination 20(1): 12-29.

[23] Sun, X. B., Zhu, J. F., Gu, Q. Y., You, Y. H. (2018): Surface-modified chitin by TEMPOmediated oxidation and adsorption of Cd (II). - Colloids and Surfaces A 555: 103-110.

[24] Tsang, D. C. W., Zhang, W. H., Lo Irene, M. C. (2007): Modeling cadmium transport in soils using sequential extraction, batch, and miscible displacement experiments. - Soil Science Society of America Journal 71(3): 674-681.

[25] Van Poucke, R., Ainsworth, J., Maeseele, M., Ok, Y. S., Meers, E., Tack, F. M. G. (2018): Chemical stabilization of Cd (II)-contaminated soil using biochar. - Applied Geochemistry 88: 122-130.

[26] Wang, J. G. (2012): Study on the adsorption and desorption characteristics of heavy metal cadmium in typical farmland soil in China. - Dissertation for doctor degree, Northwest Agricultural and Forestry University, Yangling, Shaanxi, China.

[27] Wang, L., Seki, K., Miyazaki, T., Ishihama, Y. (2009): The causes of soil alkalinization in the Songnen Plain of Northeast China. - Paddy and Water Environment 7(3): 259-270.

[28] Wang, L. L., Shi, Y., Yao, D. K., Pan, H., Hou, H. J., Chen, J., Crittenden, J. C. (2019): Cd (II) complexation with mercapto-functionalized attapulgite (MATP): adsorption and DFT study. - Chemical Engineering Journal 366: 569-576. 
[29] Wu, B., Guo, S. H., Zhang, L. Y., Li, F. M. (2018): Risk forewarning model for rice grain Cd (II) pollution based on Bayes theory. - Science of the Total Environment 618: 13431349.

[30] Xie, X. L., Gao, H. L., Luo, X., Su, T. M., Zhang, Y. Q., Qin, Z. Z. (2019): Polyethyleneimine modified activated carbon for adsorption of $\mathrm{Cd}$ (II) in aqueous solution. - Journal of Environmental Chemical Engineering 7(3): 103183.

[31] Yang, W. Z., Yang, M. D., Wen, H. Y., Jiao, Y. (2018): Global warming potential of $\mathrm{CH}_{4}$ uptake and $\mathrm{N}_{2} \mathrm{O}$ emissions in saline-alkaline soils. - Atmospheric Environment 191: 172180.

[32] Yang, X. D., Wan, Y. S., Zheng, Y. L., He, F., Yu, Z. B., Huang, J., Wang, H. L., O, Y. S., Jiang, Y. S., Gao, B.(2019): Surface functional groups of carbon-based adsorbents and their roles in the removal of heavy metals from aqueous solutions: a critical review. Chemical Engineering Journal 366: 608-621.

[33] Yuan, C. L., Li, F. B., Cao, W. H., Yang, Z., Hu, M., Sun, W. M. (2019): Cadmium solubility in paddy soil amended with organic matter, sulfate, and iron oxide in alternative watering conditions. - Journal of Hazardous Materials 378: 120672.

[34] Zhai, Q. X., Guo, Y., Tang, X. S., Tian, F. W., Zhao, J. X., Zhang, H., Chen, W. (2019): Removal of cadmium from rice by Lactobacillus plantarum fermentation. - Food Control 96: 357-364.

[35] Zhao, Y. G., Wang, S. J., Li, Y., Liu, J., Zhuo, Y. Q., Chen, H. X., Wang, J., Xu, L. Z., Sun, Z. T. (2018): Extensive reclamation of saline-sodic soils with flue gas desulfurization gypsum on the Songnen Plain, Northeast China. - Geoderma 321(1): 5260. 